\title{
Animal Bite in a 6-month-old Child and Facial Injury with Associated Unusual Nasal Injury: Management of Injuries along with 1-year Follow-up
}

\author{
Neha Sikka ${ }^{1}$, Cheranjeevi Jayam², Rama S Choudhary ${ }^{3}$, Shashi Bala ${ }^{4}$
}

\begin{abstract}
In children, accidental injuries (Al) are the most common cause of major trauma. Although rare, nonaccidental injuries (NAI) can also cause major trauma. Among NAl, animal bites form a significant fraction. Animal bites form a significant fraction of NAI in children. Amongst animal bites, dog and cat bites are the most common. In adults, the likelihood of bites is on leg/thigh but in children due to their low stature, bites are more common on scalp, head, neck, or chest region. As children have lower tissue mass/size, what appears a small wound in adults comparatively appears as a larger wound in children, causing severe disfigurement. The present paper discusses cat bite injury to maxillofacial region, distinguishing from other differential diagnoses. Potential complications, initial management, and total rehabilitation of facial injuries especially nasal injury caused by a cat in a 6-month-old child are also discussed.

Keywords: Cat bite, Facial injuries, Nasal injuries, Nasal stent, Nonaccidental injuries.

International Journal of Clinical Pediatric Dentistry (2019): 10.5005/jp-journals-10005-1683
\end{abstract}

\section{INTRODUCTION}

Nasal defects along with facial defects can occur due to congenital problems, trauma, or neoplasms. ${ }^{1}$ Among trauma, the commonest causes are road-traffic accidents (5-80.2\%), falls (7.8-48\%), sports injury (4.4-42\%), and violence (3.7-61.1\%). ${ }^{2}$ A retrospective study in India has found maxillofacial trauma commonly affecting mandible followed by nose, orbit, frontal bone, midfacial region, and nasoorbitoethmoidal fractures being the least affected. ${ }^{3}$

The most common reason for trauma in children is due to accidental injuries (Al) and is attributed to high activity of children, explorative nature, and ill-developed motor function. ${ }^{4}$ However, the other reasons for trauma should not be ruled out like alleged assault, self-inflicted injuries, child abuse-neglect (CAN), or zoonosis, all of which are collectively referred to as nonaccidental injuries (NAI). $\mathrm{NAl}$ in children are an important cause of major trauma; although rare, they should always be considered as part of diagnosis when treating trauma in children. ${ }^{5}$

Child abuse too is a major source of trauma. This can produce not only devastating physical injury but also affects the psyche of a developing child. ${ }^{6}$

Nonaccidental injuries can occur from domesticated, stray or wild animals. Children are more prone to NAI because of their playful nature, curiosity, and close approximation to animals. The very nature of child itself is to invite trouble or lack of understanding to anticipate danger. The most common animals involved are dogs, cats, and other household pets. Injuries caused by domesticated animals can range from simple love bites to devastating injuries causing impairment of function and esthetics. ${ }^{7}$

Literature is devoid of the overall management of animal bites at young age. The present paper discusses ways to diagnose, rule out other probable diagnoses, and anticipate complications of injuries caused by cats. Also included are the initial management and total rehabilitation of injuries caused by cats in a 6-month-old child. \begin{tabular}{l}
\hline 1,4Department of Dental Materials, Post Graduate Institute of Dental \\
Sciences, Rohtak, Haryana, India \\
${ }^{2}$ Department of Dentistry, All India Institute of Medical Sciences, \\
Mangalagiri, Andhra Pradesh, India \\
${ }^{3}$ Department of Dentistry, Tata Main Hospital, Jamshedpur, Jharkand,
\end{tabular} India

Corresponding Author: Neha Sikka, Department of Dental Materials, Post Graduate Institute of Dental Sciences, Rohtak, Haryana, India, Phone: +91 9416330633, e-mail: neha.nehasikka@gmail.com

How to cite this article: Sikka N, Jayam C, Choudhary RS, et al. Animal Bite in a 6-month-old Child and Facial Injury with Associated Unusual Nasal Injury: Management of Injuries along with 1-year Follow-up. Int J Clin Pediatr Dent 2019;12(6):560-565.

Source of support: Nil

Conflict of interest: None

\section{Case Description}

A 6-month-old female child along with parents presented to us with a complaint of facial wounds. The history as narrated by the father was unfitting regarding the cause and severity of facial wounds; as history was unsuitable, both parents were separated and a precise timeline of events was questioned separately. Important questions included (a) nature and type of injuries; (b) parents' location at the time of injuries; (c) socioeconomic status; (d) presence of any substance misuse; (e) presence of any domestic violence; and (f) employment history.

History of the patient dated back 4-5 days when the child was attacked by a cat while she was sleeping. The cat was a nondomesticated one. The cat bite resulted in the clefting of the upper lip and scarring all over the midfacial region (Fig. 1). The scarring was so severe that it might lead to the occlusion of the nostrils.

During the history taking, we suspected the patient to be a case of CAN due to following reasons: dissimilar history

(C) The Author(s). 2019 Open Access This article is distributed under the terms of the Creative Commons Attribution 4.0 International License (https://creativecommons. org/licenses/by-nc/4.0/), which permits unrestricted use, distribution, and non-commercial reproduction in any medium, provided you give appropriate credit to the original author(s) and the source, provide a link to the Creative Commons license, and indicate if changes were made. The Creative Commons Public Domain Dedication waiver (http://creativecommons.org/publicdomain/zero/1.0/) applies to the data made available in this article, unless otherwise stated. 
given by parents, the impossibility of injuries in infant who was immobile, severity of the injury out of proportion to the event described, need for treatment of symptoms, our initial assessment of parental attitude, and low-socioeconomic status (a predisposing factor).

Since it was suspected to be a case of CAN, the child was examined separately. A fully undressed Head-to-Toe inspection of the child was conducted: The possibility of any head injury was ruled out on examination; the presence of other injuries in other parts of the body was examined; and photographs of the wounds were taken. Further investigations, like radiographs and swabs for culture sensitivity, were conducted. Referral to pediatrician was also done.

\section{Provisional Diagnosis}

Trauma due to cat bite or child abuse.

\section{Investigations}

Radiographs and antibiotic sensitivity test.

\section{Confirmatory Diagnosis}

Trauma due to cat bite.

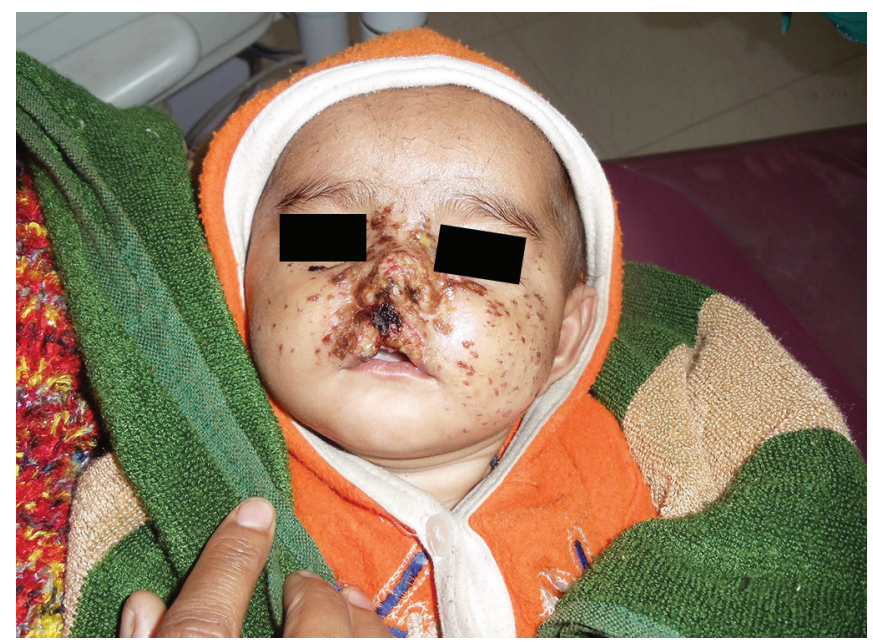

Fig. 1: View of patient during first visit at clinic; severe injuries, clefting of upper lip, and scarring noted in midfacial region

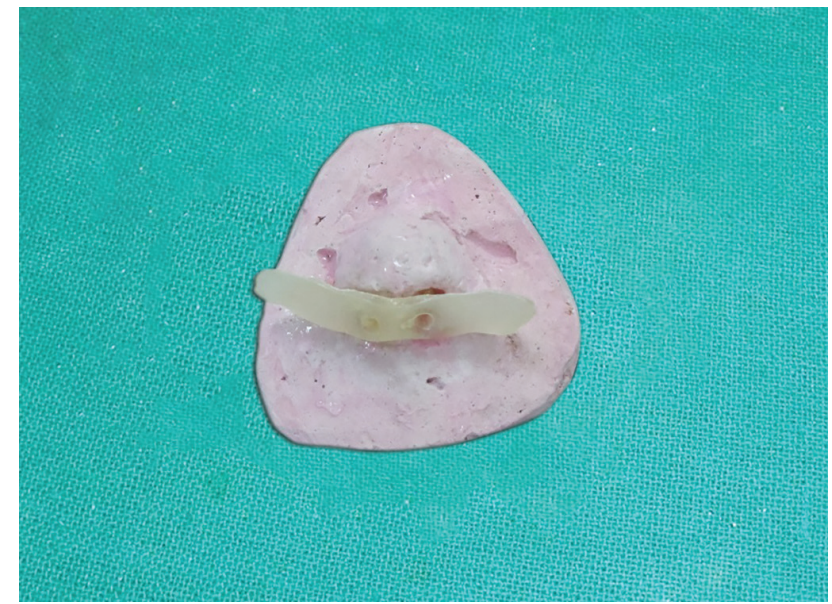

Fig. 3: Fabrication of extraoral portion of appliance made on cast from different child patient of same age

\section{Treatment and Follow-up}

We ensured that the parents realize the extent and nature of the problem. Scarring was so severe that it might lead to the occlusion of the nostrils if not supported by a nasal stent.

Thus, the fabrication of a nasal stent was planned to support the nostrils, maintain a patent airway, and prevent further cicatrization.

As the patient's face was heavily scarred, conventional impression procedures were impossible. Thus, it was planned to use the cast of another pediatric patient of the same age.

The appliance was fabricated in two stages: intranasal portion was fabricated on the sectional cast of one patient (Fig. 2) followed by the fabrication of extranasal portion on the cast of another patient (Fig. 3) using a clear autopolymerizing acrylic resin. Holes were drilled in the intranasal portion of the appliance to maintain a patent airway. The appliance was adjusted according to the patient and thoroughly polished before insertion (Fig. 4). Special care was taken so that the extranasal portion of the appliance does not contact the facial skin of the patient (Fig. 5). The appliance was secured in place with the help of straps tied to the occiput. The patient was followed every week for 1 month. Complete resolution of the facial scars was observed on 1-month follow-up making impression procedures possible (Fig. 6). Intranasal and extranasal impressions using impression compounds were made for the fabrication of a new

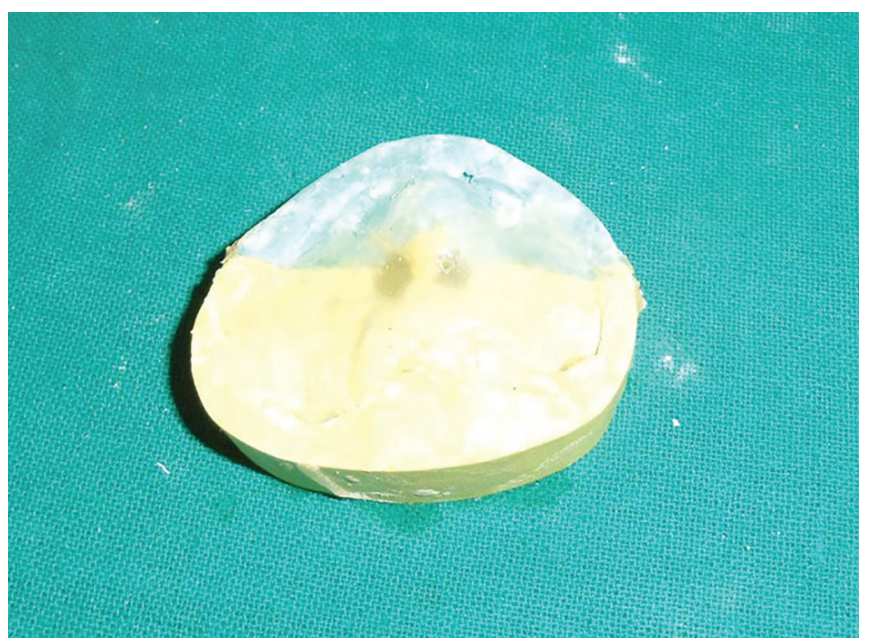

Fig. 2: Fabrication of intranasal portion of appliance on sectional cast from patient

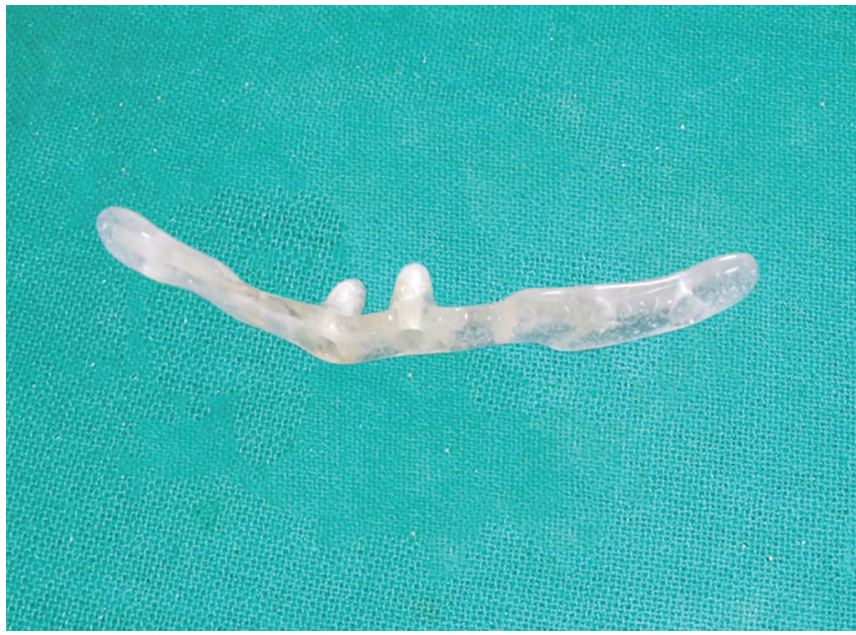

Fig. 4: Fabricated nasal stent 


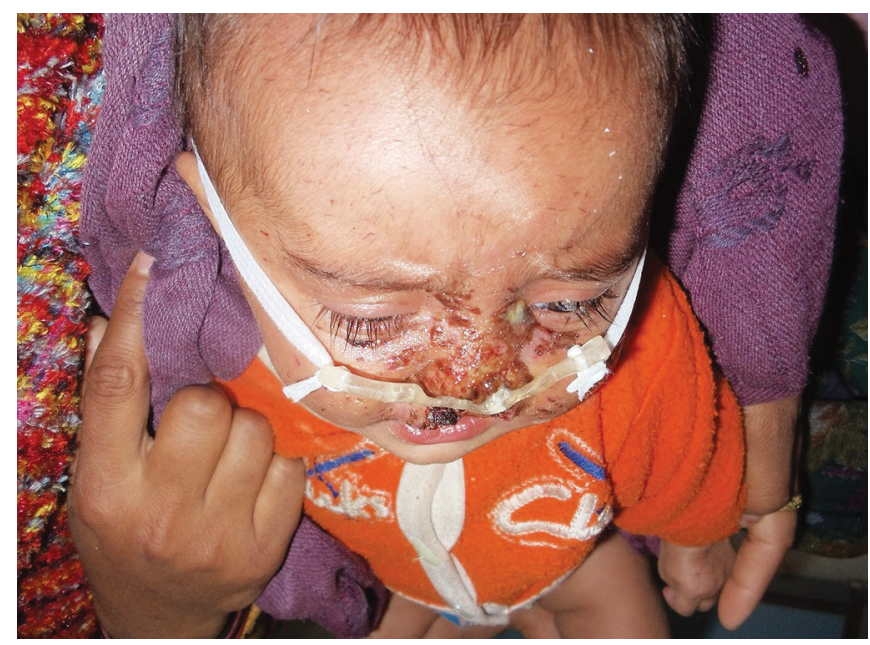

Fig. 5: Appliance secured in place with the help of straps tied to the occiput

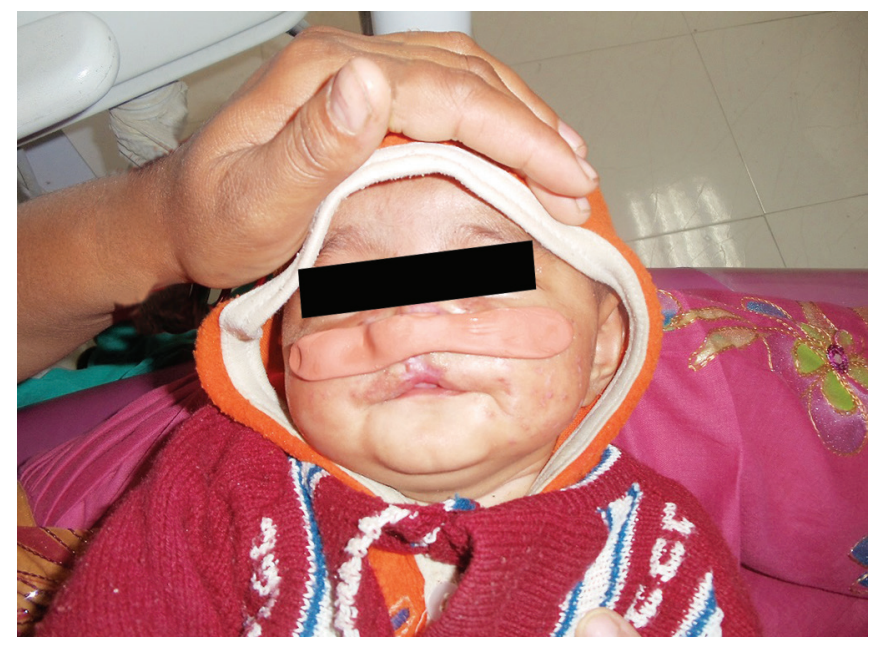

Fig. 7: Impression procedure using impression compound

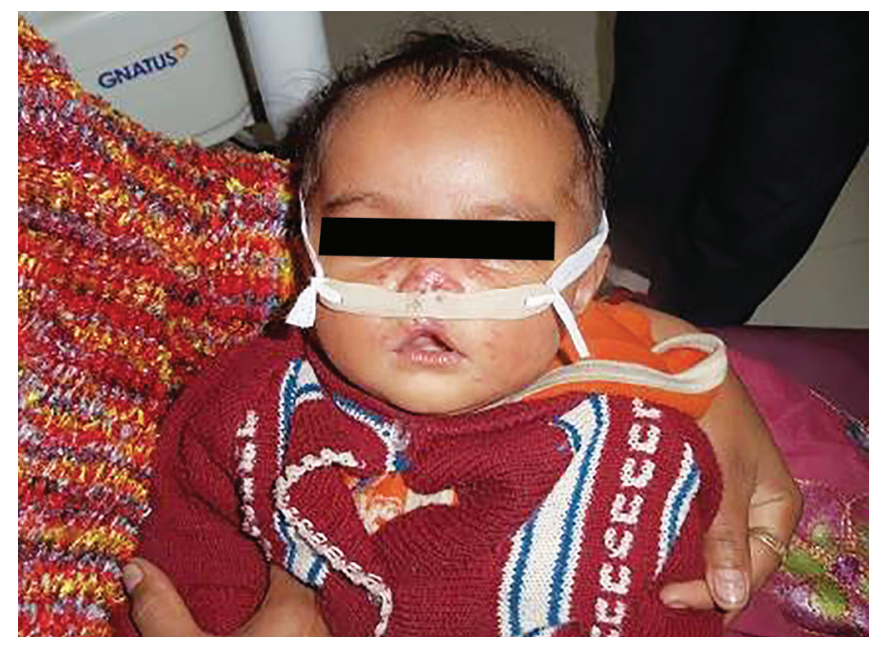

Fig. 9: Customized nasal stent in position

appliance (Fig. 7). The appliance was fabricated by investing these impressions into plaster, thus fabricating a sectional mold (Fig. 8). The impression compound in the sectional mold was replaced by a clear



Fig. 6: One-month follow-up showing resolution of scars in face

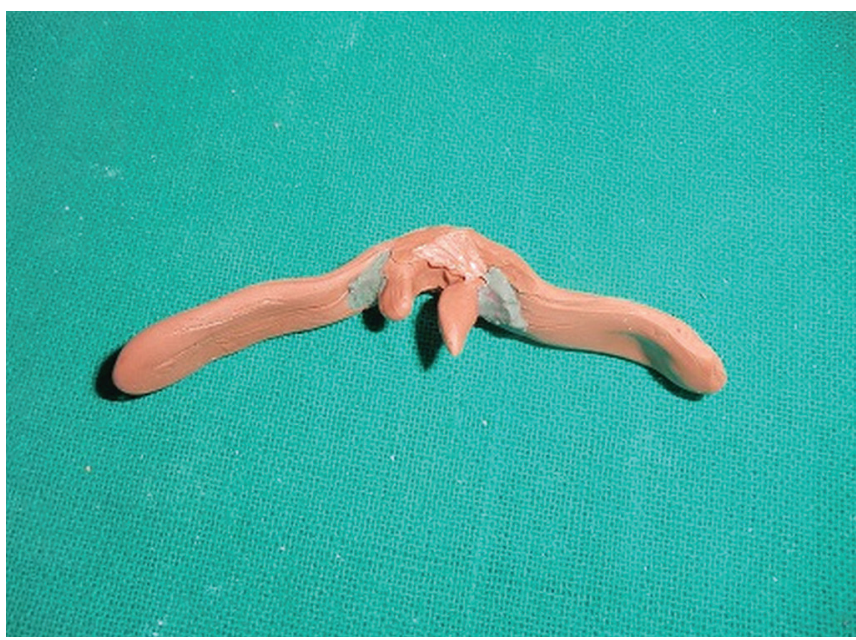

Fig. 8: Final impression with impression compound

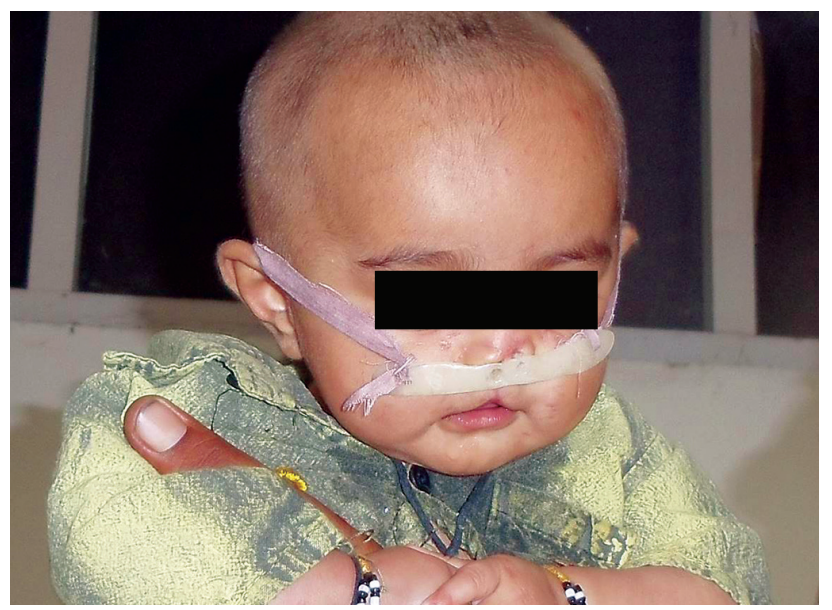

Fig. 10: Follow-up showing resolution of facial scars and continued wear of appliance at 3-month follow-up period

autopolymerizing acrylic resin. The patency holes were made; the appliance was polished and inserted (Fig. 9). A biweekly follow-up was maintained for the next 2 months (Fig. 10). 


\section{Discussion}

Children are more prone to animal attacks because of their exploring nature and inability to restrain from danger before it happens; their provoking behavior is more likely to aggravate a bite. Provocation may be due to simple play, tease, or abuse with animals. In the present case, the child was very young to provoke the animal; the cause of injury is unknown. So, the suspicion can range from animal injuries to child abuse, all of which should form a part of the differential diagnosis. Differential diagnosis is very important because bites from unprovocative animals (the child was very young to suspect provocation) should provide as suspicion of more morbid disease like rabid cat or need for diagnosing CAN is important to prevent further abuse in the child.

Zoonosis is an animal disease that is transmissible to humans. American Pet Association approximates 77 million cats in the USA every year. In Pune (India), cat bites accounted for approximately $10-20 \%$ of all animal bites in 2011 itself. ${ }^{8}$ Most cat bites (about 70\%) are caused by pet cats. Cats are predators and react erratically in certain circumstances, especially the undomesticated ones. ${ }^{9}$ Older women are often bitten on the hand while feeding or stroking a cat. Injuries caused by cats can cause one or a combination of the following:

- Physical injuries due to bite or scratch.

- Infectious diseases like rabies.

- Secondary infections from:

- Cat saliva (Bacteroides, Pasteurella, and Porphyromonas species can cause fatal complications, such as cellulitis, meningitis, lung abscess, cat-scratch disease, tetanus, or rabies.),

- Cat-scratch disease, and

- Transmission of arthropod vectors like ticks and fleas. ${ }^{10,11}$

Usually, dogs have rounded teeth and strong jaws producing crushing injuries. On the contrary, cats being the second most common biters produce lacerations and punctures because of its sharp and narrow teeth. Cat bites produce smaller skin opening while penetrate deeper into muscles and bones; such bites produce devastating infection because of spread along deeper planes. Contrastingly, human bites produce shallow tears and bruising. ${ }^{12}$

In adults, the likelihood of the bites is to leg or thigh but in children due to their low stature, bites are common to scalp, head, neck, or chest region too. Due to lower tissue mass/size in children, what appears a small wound in adults appears proportionally larger in children leading to greater disfigurement. In the present case, the child had bites and scratches in the face leading to severe scarring of face. ${ }^{13}$

Management for animal wounds can be summarized with acronym-“HELICOPTER"

- $\mathrm{H}$-detailed history

- E-proper general examination

- L-liberal cleansing-actual means reducing the chances of infection

- I-generous irrigation

- C-closure of wounds and culture sensitivity-as multiple organisms are involved, sensitivity for organisms is of importance

- O-operative cleansing-deeper wounds should be carefully explored for fragments before definitive surgical management
Table 1: Classification of dog bite problems in facial region by Lackmann et al.

\begin{tabular}{ll}
\hline I & No muscle involvement; only surface injuries \\
IIA & Muscle involvement due to deep injuries \\
IIB & $\begin{array}{l}\text { Through and through wound between external surface } \\
\text { and oral mucosa }\end{array}$ \\
IIIA & $\begin{array}{l}\text { Deep injuries with avulsion of tissue } \\
\text { Deep avulsive injuries with ear/nasal cartilage } \\
\text { IIIB }\end{array}$ \\
IVA & $\begin{array}{l}\text { Deep injuries alongside parotid duct/facial nerve } \\
\text { involvement }\end{array}$ \\
IVB & Deep injuries alongside concomitant bony involvement \\
\hline
\end{tabular}

- $\mathrm{P}$-prophylactic immunization and antimicrobial agents

- T-tetanus immunization status-active or passive tetanus prophylaxis based on immunization status

- E-elevation-primary closure by flaps is indicated if there is significant loss of tissue

- R-rabies prevention.,13-15

Lackmann et al classification acts as a clinical guideline for treatment in pediatric patients (Table 1) ${ }^{16}$ In the present child, the injuries can be classified into III-B type.

While treating, facial wounds esthetics is of utmost importance. Facial wounds are at low risk of complications compared with other parts due to good blood supply. ${ }^{17}$ Usually, cat bites are deeper and risk of infection is greater; in such cases, primary closure of wounds is not indicated. However on the contrary, facial injuries require primary closure of wounds to prevent scarring that can lead to disfigurement. Facial injuries require only minimal trimming of wound edges because facial tissues can persist on small pedicles too. ${ }^{18}$ In children, due to greater proportion of tissue involved requiring suturing of wounds in turn producing awful deformity due to scarring. ${ }^{13}$ All of the above considerations should be borne in mind during initial management of wounds. Bite injuries involving cartilage require delayed closure. In this child, since the nose was involved, delayed closure was done while primary closure and generous irrigation-wound cleansing-antiseptic application were done for other regions. ${ }^{18}$ In our case, all of the considerations were done and appropriate wound management was accomplished. The repair of the cleft in the upper lip was planned to be done after the child reaches the age of 5 years.

Previous literature is loaded with information regarding the initial management of animal bite; however, definitive management for facial wounds is lacking. There is no consensus on final rehabilitation procedures due to fewer studies present. Management options range from no reconstruction to local flap adjustments, autologous reconstruction, or external silicone prosthesis. ${ }^{19}$

In the present case, severity of facial injuries prompted us not only to look at initial management, but also the overall management. The severity of nasal scarring required special attention and the child's age was a deterrent. Cast from the different patient had to be used initially because of the inability to take impression due to the severity of injuries. Behavior management of child and parent counseling due to lack of parent knowledge was attained looking at the long duration of treatment for complete rehabilitation. There is no reported case of using nasal stent for animal bites in children in literature. 
Nasal stent in the present case was fabricated using a clear acrylic resin for maintaining the patency of the nasal orifices and maintaining the form of nose. Several materials for fabricating a custom nasal stent have been discussed in the literature; some of them are dental waxes, silicone suction tube tips, and clear acrylic resin. A recent comparative study has shown customized acrylic stents to provide good results as they maintained the desired shape and was less visible compared with the other materials. $^{20}$

Trauma due to $\mathrm{Al}$ is the commonest, however other causes (NAI), such as animal-caused injuries or CAN can be a source of major injuries and should be a part of the differential diagnosis., 5, Following paragraphs explain how CAN should be diagnosed or ruled out.

In routine clinical setting, CAN usually goes unnoticed. ${ }^{6}$ Several reasons for this are (a) insufficient knowledge in dental curriculum leading to inadequate knowledge among practitioners, (b) inability of service provider to recognize CAN in normal clinical setting, (c) lack of desire/feeling of embarrassment in dealing with such cases, and (d) disinclination to get involved in medicolegal cases. ${ }^{21,22}$

The authors would like to summarize a few easy tips in recognizing $\mathrm{CAN}$ from $\mathrm{Al}$ :

- While history taking - (a) unfitting history for cause, severity, type, and location of injuries; (b) injury inconsistent with child's developmental capability; (c) vague answers; (d) delay in seeking care; (e) pursuing treatment only for emergency and severe disabilities/pain relief; and (f) missing appointments.

- Caregiver approach-presence of violent outbursts toward children, careless attitude, unwarranted behavior in clinic, and poor knowledge about child's daily routines.

- Child behavior-fearful, nervous, timid/shy, and restrained behavior of child.

- Manifestations in general examination-(a) unusual type of injuries, (b) presence of multiple injuries, (c) presence of injuries at unusual sites, and (d) injuries at various stage of healing suggestive of chronological pattern of occurrence.

- Social determinants (predisposing factors)-low-economic status, unemployment of caregiver, domestic violence, and substance misuse. ${ }^{6,21,22}$

By rule, it is imperative that every case of CAN should be recognized, registered, and later reported. Treatment should be provided unlike normal cases with extra effort for rehabilitation of child and the care giver. ${ }^{23}$

In the present case, we suspected CAN in this patient because of unfitting history (cat bite would not cause such grave injuries), presence of vague answers by parents, no precision in the timeline of events surrounding the injuries between mother and father, slight embarrassment by father while discussing trauma, our initial assessment of parental attitude, symptomatic treatment, and socioeconomic status. However, we could not confirm since it was not a clear case of CAN; difficulties in establishing CAN were the inability to establish correct communication with parents due to language barrier and, inability to distinguish whether it was neglectful attitude vs lack of knowledge in understanding the severity of injuries to seek treatment. So, CAN was only suspected, noted down but not reported; it was decided to watch parents' overtime during treatment phases. However, the possibility of CAN was rejected while watching parents overtime, absence of child's fear of being with parents, absence of violent outbursts toward the child, absence of any old injuries in child and with the fact that the parents maintained the follow-up appointments of the child.

\section{Conclusion}

Due to lower tissue mass/size in children, what appears a small wound in adults appears proportionally larger in children leading to greater disfigurement and management is of utmost importance.

\section{Learning Points/Take Home Message}

- Apart from accidents, child abuse or animal trauma should be a part of the differential diagnosis.

- Cat bites produce smaller skin opening while penetrate deeper into muscles and bones; such bites produce devastating infection because of spread along deeper planes.

- Overall management inclusive of initial management is required for a good prognosis of facial injuries in children.

- Parent counseling regarding injuries and need for treatment and; behavior management of children is important for longterm prognosis.

\section{References}

1. Nagaraj E, Shetty M, Krishna PD. Definitive magnetic nasal prosthesis for partial nasal defect. Indian J Dent Res 2011;22(4):597-599. DOI: 10.4103/0970-9290.90309.

2. Ferreira PC, Amarante JM, Silva PN. Retrospective study of 1251 maxillofacial fractures in children and adolescents. Plast Reconstr Surg 2005;115(6):1500-1508. DOI: 10.1097/01.PRS.0000160268. 20294.FD.

3. Faust RA, Maxillary fractures in children. WebMD Web site. Available from. http://www.emedicine.com/ent/topic491.htm. [Accessed June 2006.].

4. Neeraja G, Bharadwaj S, Shah K, et al. Knowledge, attitude, and practices regarding oro-facial injuries and oro-facial protective devices among physical instructors in Bengaluru. J Int Oral Health 2014;6(3):1-6.

5. Aren G, Sepet E, Pınar Erdem A, et al. Predominant causes and types of orofacial injury in children seen in the emergency department. UlusTravma Acil Cerrahi Derg 2013;19(3):246-250. DOI: 10.5505/ tjtes.2013.75688.

6. Starr M, Klein EJ, Sugar N. A perplexing case of child abuse: oral injuries in abuse and physician reporting responsibilities. Pediatr Emerg Care 2015;31(8):581-583. DOI: 10.1097/PEC.0000000000000286.

7. Avner JR, Baker MD. Dog bites in urban children. Pediatrics 1991;88(1):55-57.

8. Shetty RA, Chaturvedi S, Singh Z. Profile of animal bite cases in Pune. J Commun Dis 2005;37(1):66-72.

9. MacBean CE, Taylor DM, Ashby K. Animal and human bite injuries in Victoria, 1998-2004. Med J Aust 2007;186:38. DOI: 10.5694/j.13265377.2007.tb00787.x.

10. Talan DA, Citron DM, Abrahamian FM, et al. Bacteriologic analysis of infected dog and cat bites. Emergency medicine animal bite infection study group. N Engl J Med 1999;340(2):85-92. DOI: 10.1056/ NEJM199901143400202.

11. Goldstein EJ, Citron DM, Wield B, et al. Bacteriology of human and animal bite wounds. J Clin Microbiol 1978;8(6):667-672.

12. Dire DJ. Cat bite wounds: risk factors for infection. Ann Emerg Med 1991;20(9):973-979. DOI: 10.1016/S0196-0644(05)82975-0.

13. Rohrich RJ. Man's best friend revisited: who's watching the children? Plast Reconstr Surg 1999;103(7):2067-2068. DOI: 10.1097/00006534199906000-00045. 
14. Brook I. Microbiology and management of human and animal bite wound infections. Prim Care 2003;30(1):25-39. DOI: 10.1016/S00954543(02)00056-8.

15. Brook I. Management of human and animal bite wounds: an overview. Adv Skin Wound Care 2005;18(4):197-203. DOI: 10.1097/00129334200505000-00008.

16. Lackmann GM, Draf W, Isselstein G, et al. Surgical treatment of facial dog bite injuries in children. J Craniomaxillofac Surg 1992;20(2):81-86. DOI: 10.1016/S1010-5182(05)80472-X.

17. Callaham M. Prophylactic antibiotics in common dog bite wounds: a controlled study. Ann Emerg Med 1980;9(8):410-414. DOI: 10.1016/ S0196-0644(80)80153-3.

18. Donkor P, Bankas DO. A study of primary closure of human bite injuries to the face. J Oral Maxillofac Surg 1997;55(5):479-481. DOI: 10.1016/ S0278-2391(97)90695-9.
19. Stewart K, Majdak-Paredes E. Injury patterns and reconstruction in acquired ear deformities. Facial Plast Surg 2015;31(6):645-656. DOI: 10.1055/s-0035-1568140.

20. Pavithran P, Pujary K, Mahesh SG. Customised acrylic nasal stents following recanalisation of modified Young's procedure. J Laryngol Otol 2010;124(8):864-867. DOI: 10.1017/S0022215110000642.

21. Crespo $M$, Andrade $D$, Alves $A L$, et al. The dentist's role in the child abuse: diagnosis and report. Acta Med Port 2011;24(4):939-948.

22. Needleman HL. Orofacial trauma in child abuse: types, prevalence, management, and the dental profession's involvement. Pediatr Dent 1986;8:71-80.

23. Thompson LA, Tavares M, Ferguson-Young $D$, et al. Violence and abuse: core competencies for identification and access to care. Dent Clin North Am 2013;57(2):281-299. DOI: 10.1016/j.cden.2013. 01.003 . 